\title{
CLINICODEMOGRAPHIC PROFILE AND RISK FACTORS OF STROKE IN DIABETIC AND NONDIABETIC PATIENTS IN VINDHYA REGION
}

\author{
Praveen Kumar Baghel' ${ }^{1}$ Keshav Singh², Jitendra Kumar Dandotiya ${ }^{3}$
}

1 Professor, Department of Medicine, Shyam Shah Medical College, Rewa, Madhya Pradesh, India.

${ }_{2}^{2}$ Associate Professor, Department of Medicine, Shyam Shah Medical College, Rewa, Madhya Pradesh, India.

${ }^{3}$ Resident Medical Officer, Department of Medicine, Shyam Shah Medical College, Rewa, Madhya Pradesh, India.

\section{ABSTRACT}

\section{BACKGROUND}

Stroke is defined as abrupt onset of neurologic deficit that is attributable to a focal vascular cause. It represents the second most common cause of mortality and the third most common cause of disability in developed countries. Diabetes is an important risk factor for ischemic stroke and the risk of ischemic stroke in patients with diabetes is twice as in those without diabetes. Hence the need of a study to assess the pattern of stroke, clinical profile and risk factors in diabetes mellitus and nondiabetic patients.

\section{MATERIALS AND METHODS}

This was a cross sectional study conducted on 500 patients of stroke for a duration of one year. Written informed consent was taken from all patients. History, clinical examination and radiological investigations (CT Scan/ MRI) was done for confirmation of stroke. Haematological and biochemical examination (HbA1c and Lipid profile) were done. ECG was done to rule out CAD.

\section{RESULTS}

Out of 500 patients, $72.8 \%$ had ischemic stroke and $27.2 \%$ had haemorrhagic stroke. Diabetic patients had greater probability of ischemic stroke (81.73\%). Stroke was more common in males with a male to female ratio of 1.52:1. (60.4\% vs 39.6\%). Young stroke ( $\leq 45$ year) comprised of $12.8 \%$ patients. $52.4 \%$ patients were hypertensive. In diabetic group, hypertension was present in $60.09 \%$ and in nondiabetics $46.91 \%$, and this was significant ( $\mathrm{p}$ value-0.00046). Diabetic hypertensives have significant association with ischemic stroke. $86.5 \%$ of the diabetic patients had HbA1c $>6.5 \%$ reflecting poor glycemic control. 99.3\% patients in nondiabetic group had HbA1c $<6.5 \%$. HbA1c is positively associated with ischemic stroke ( $\mathrm{p}-$ value was $<0.05$ ).

\section{CONCLUSION}

This study shows that diabetes mellitus increases the risk of ischemic stroke. Diabetic stroke patients were younger as compared to nondiabetic stroke patients. Hypertension, poor glycemic control, dyslipidemia, obesity, smoking and tobacco chewing increases the risk of ischemic stroke. Thus, we can use glycemic control, HbA1c and duration of diabetes as a predictor of stroke

\section{KEY WORDS}

Stroke, Diabetic, Nondiabetic, HbA1c.

HOW TO CITE THIS ARTICLE: Baghel PK, Singh K, Dandotiya JK. Clinicodemographic profile and risk factors of stroke in diabetic and nondiabetic patients in Vindhya region. J. Evolution Med. Dent. Sci. 2019;8(01):29-33, DOI: 10.14260/jemds/2019/7

\section{BACKGROUND}

A Stroke is defined as an abrupt onset of neurologic deficit that is attributable to a focal vascular cause.[1] Stroke can be divided into two broad categories ischemic stroke and haemorrhagic stroke. There are several modifiable risk factors for stroke including hypertension, diabetes mellitus, smoking and dyslipidaemia. Diabetes mellitus is one of the well known risk factor for stroke ${ }^{2]}$ and the risk of ischemic stroke in patients with diabetes is twice than those without diabetes. Worldwide stroke is the second most common cause of mortality and the third most common cause of disability.[3] In India Stroke prevalence rate is $471.58 / 10000 .{ }^{[4]}$ It is well known that diabetes mellitus may

'Financial or Other Competing Interest': None.

Submission 27-11-2018, Peer Review 20-12-2018,

Acceptance 29-12-2018, Published 07-01-2019.

Corresponding Author

Dr. Keshav Singh,

Associate Professor

Department of Medicine,

Shyam Shah Medical College,

Rewa, Madhya Pradesh, India.

E-mail: keshavsingh19@yahoo.com

DOI: $10.14260 /$ jemds $/ 2019 / 7$

\section{(c) $(\mathbf{5})$}

cause systemic and intracranial atherosclerotic disease and this increased risk has been linked to the pathophysiological changes seen in the cerebral vessels of patients with diabetes. The combined role of $\mathrm{HbA1c}$, microvascular complications, low HDL cholesterol, and treatment with insulin plus oral agents highlights the importance of diabetes mellitus history and clinical background in the development of stroke.

Men have a higher incidence of stroke than women at younger but not older ages, with the incidence reversed and higher for women by age 75 years and older.[5]

Our study is aimed at analysing the epidemiological, radiological profile of diabetic and Nondiabetic stroke patients of Vindhya region admitted in Sanjay Gandhi hospital Rewa (MP). As few studies have been conducted in Asian countries portraying role of $\mathrm{HbA1c}$ and duration of diabetes with risk of stroke, our study may help in analysing correlation of $\mathrm{HbA} 1 \mathrm{c}$ levels and duration of diabetes with type of stroke.

\section{MATERIALS AND METHODS}

The present study was conducted in Department of Medicine, Sanjay Gandhi Memorial Hospital, associated with Shyam Shah Medical College, Rewa between April 2017 to March 2018 (12 Months). 


\section{Study Design \\ Cross sectional study.}

\section{Duration of Study}

01 year from April 2017 to March 2018.

\section{Sample Size}

500 patients of stroke.

\section{Inclusion Criteria}

All patients older than 18 years presenting clinically and radiologically with feature of stroke.

\section{Exclusion Criteria}

1. Age less than 18 years.

2. Stroke due to other causes.

- History of head injury.

- Drugs.

- Hypercoagulable stroke.

- Eclampsia.

- Infection.

- Sub Arachnoid Haemorrhage.

\section{Data Collection}

This was a cross sectional study conducted on 500 patients of stroke who fulfil inclusion criteria was taken for this study for a duration of one year. Written informed consent was taken from all patients. History, clinical examination and radiological investigation (CT-Scan/MRI Head) was done. Diabetic and non-diabetics were defined as per American Diabetes association 2003 criteria of $\mathrm{HbA} 1 \mathrm{c}(<5.7 \%$ normal, $5.7 \%$ to $6.4 \%$ impaired glucose tolerance $\geq 6.5 \%$ diabetes). Hypertension was defined as systolic blood pressure $>140$ $\mathrm{mm} \mathrm{Hg}$ and diastolic pressure $>90 \mathrm{mmHg}$. Dyslipidaemia was diagnosed when LDL cholesterol was $>100 \mathrm{mg} / \mathrm{dl}$, HDL cholesterol was $<40 \mathrm{mg} / \mathrm{dl}$ and Triglyceride was $>150 \mathrm{mg} / \mathrm{dl}$. HbA1c was measured by high performance liquid chromatography method. Diabetic and non-diabetic patients were further grouped according to type of stroke. Co-relation between Ischemic Stroke and level of HbA1c was find out.

\section{Statistical Analysis}

Statistical analyses were carried out using a computer based statistical analysis programme, SPSS (Statistical Program for Social Sciences) version 22.0. The Chi Square was used wherever comparisons were needed between the two groups or between two categories in the same group. A p value < 0.05 was considered significant. The analysed data was graphically represented by, bar graphs etc.

\section{RESULTS}

\begin{tabular}{|c|c|c|c|}
\hline Variable & Category & $\begin{array}{c}\text { Diabetic } \\
\text { (n=208) }\end{array}$ & $\begin{array}{c}\text { Non-Diabetic } \\
\text { (n=292) }\end{array}$ \\
\hline \multirow{2}{*}{ Gender } & Male & 132 & 170 \\
\cline { 2 - 4 } & Female & 76 & 122 \\
\hline \multirow{4}{*}{$\begin{array}{c}\text { Age } \\
\text { Group }\end{array}$} & $18-30$ & $2(0.96 \%)$ & $3(1.02 \%)$ \\
\cline { 2 - 4 } & $31-40$ & $5(2.4 \%)$ & $16(5.47 \%)$ \\
\cline { 2 - 4 } & $41-50$ & $29(13.9 \%)$ & $52(17.8 \%)$ \\
\cline { 2 - 4 } & $51-60$ & $68(32.7 \%)$ & $42(14.3 \%)$ \\
\cline { 2 - 4 } & $61-70$ & $62(29.8 \%)$ & $61(20.8 \%)$ \\
\hline \multirow{4}{*}{} & $>70$ & $42(20.1 \%)$ & $118(40.4 \%)$ \\
\hline
\end{tabular}

\begin{tabular}{|c|c|c|c|c|}
\hline \multirow[b]{2}{*}{$\begin{array}{l}\text { Type of } \\
\text { stroke }\end{array}$} & \multicolumn{2}{|c|}{ Ischemic stroke } & 170 & 194 \\
\hline & \multicolumn{2}{|c|}{$\begin{array}{l}\text { Haemorrhagic } \\
\text { stroke }\end{array}$} & 38 & 98 \\
\hline \multirow{2}{*}{ Resident } & \multicolumn{2}{|c|}{ Rural } & 96 & 176 \\
\hline & \multicolumn{2}{|c|}{ Urban } & 112 & 116 \\
\hline BMI $\left(\mathrm{kg} / \mathrm{m}^{2}\right)$ & & & $22 \pm 4.6$ & $21.6 \pm 4.2$ \\
\hline \multirow{4}{*}{$\begin{array}{c}\text { Waist } \\
\text { circumference }\end{array}$} & \multirow[b]{2}{*}{ Male } & $<90 \mathrm{~cm}$ & $47(35.6 \%)$ & $103(61 \%)$ \\
\hline & & $\geq 90 \mathrm{~cm}$ & $85(64.3 \%)$ & $67(39.4 \%)$ \\
\hline & \multirow{2}{*}{ Female } & $<85 \mathrm{~cm}$ & $27(35.5 \%)$ & $70(57.3 \%)$ \\
\hline & & $\geq 85 \mathrm{~cm}$ & $49(64.4 \%)$ & $53(43.45 \%)$ \\
\hline \multirow{4}{*}{$\begin{array}{l}\text { Waist Hip } \\
\text { Ratio }\end{array}$} & \multirow{2}{*}{ Male } & $<0.9$ & $44(33.3 \%)$ & $112(65.8 \%)$ \\
\hline & & $\geq 0.9$ & $88(66.6 \%)$ & $58(34.1 \%)$ \\
\hline & \multirow[b]{2}{*}{ Female } & $<0.8$ & $30(39.5 \%)$ & $73(59.85 \%)$ \\
\hline & & $\geq 0.8$ & $46(60.5 \%)$ & $49(40.1 \%)$ \\
\hline \multicolumn{5}{|c|}{$\begin{array}{l}\text { Table 1. Clinical Profile of Diabetic and Non-Diabetic } \\
\text { Stroke Patients }\end{array}$} \\
\hline
\end{tabular}

In our study out of 500 stroke patients, 208(41.6\%) were diabetic stroke and 292(58.4\%) were nondiabetic stroke. Out of 500 patients 302 were male\& 198 were female. Stroke was more common in male with male: female ratio is $1.52: 1$. In diabetic group male-female ratio was $1.73: 1$ compared to 1.39:1 in non-diabetics.

The age range was 18 to 100 year, mean age \pm SD in total study population was $60.86 \pm 12.51$ years. In diabetics Mean age \pm SD was $59.25 \pm 11.13$ years and in non-diabetics Mean age \pm SD was $62.03 \pm 12.30$. Young stroke ( $\leq 45$ year) patients was $12.8 \%$. In Non -diabetic group maximum number of patients $(40.4 \%)$ were of $>70$-year age group compared to diabetic patients where maximum number of patients (32.69\%) belonged to 51-60 years age group.

In total study population the percentage of Haemorrhagic stroke was $27.2 \%$ and the percentage of ischemic stroke was $72.8 \%$. in diabetic group ischemic stroke patients were $81.73 \%$ and haemorrhagic stroke patients were $18.26 \%$. In Nondiabetic group ischemic stroke patients were $66.43 \%$ and haemorrhagic stroke patients were $33.53 \%$. Diabetic patients have greater probability of having Ischemic stroke (p-value was $<0.0002$ )

In our study prevalence of stroke was slightly higher in the rural population (54.4\%) as compared to urban population $(45.6 \%)$.

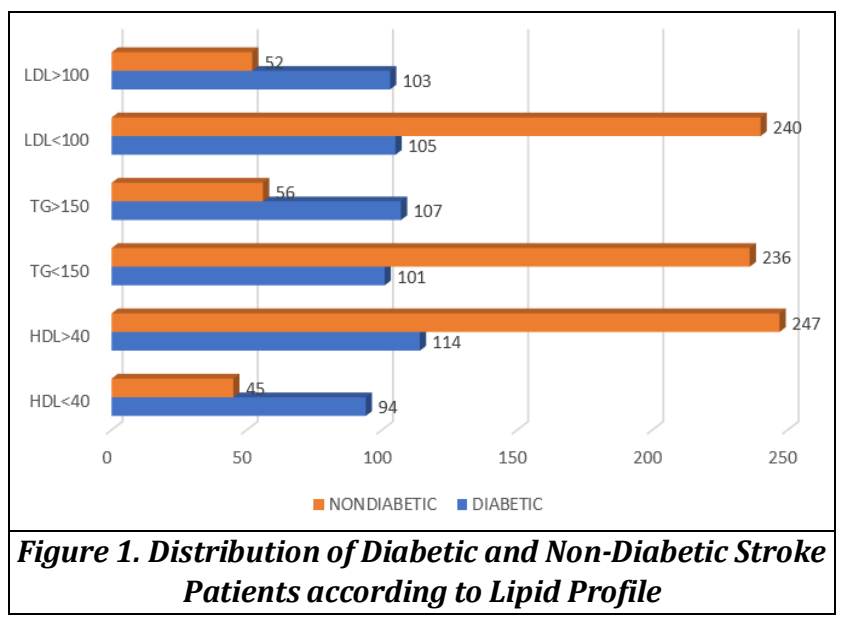

In our study HDL level $<40 \mathrm{mg} / \mathrm{dl}$ was present in $27.8 \%$ of the patients. Among Diabetic it was $45.8 \%$ and in nondiabetics it was $15.4 \%$ ( $p$ value was <.05). DM patients have significant association with low HDL. 
TG $>150 \mathrm{mg} / \mathrm{dl}$ was found in $32.6 \% \%$ of total cases. It was $51.44 \%$ in diabetics compared to $19.17 \%$ in nondiabetics and this finding was significant $\mathrm{p}$ value was $<0.05$. DM patients have significant association with high triglyceride.

LDL level $>100$ was found in $31 \%$ of total cases. It was $49.5 \%$ in diabetics compared to $17.80 \%$ in non-diabetics and this finding was significant ( $p$ value $<0.05$ ) suggesting DM patients have significant association with high LDL.

\begin{tabular}{|c|c|c|c|}
\hline $\begin{array}{c}\text { Risk } \\
\text { Factors }\end{array}$ & Category & $\begin{array}{l}\text { Diabetic } \\
(n=208)\end{array}$ & $\begin{array}{c}\text { Non-Diabetic } \\
(n=292)\end{array}$ \\
\hline \multirow{2}{*}{ Smoking } & Present & $68(32.7 \%)$ & $61(20.9 \%)$ \\
\hline & & $140(67.32 \%)$ & $231(79.1 \%)$ \\
\hline \multirow{2}{*}{$\begin{array}{l}\text { Tobacco } \\
\text { chewing }\end{array}$} & Prese & $93(44.7 \%)$ & $116(39.7 \%)$ \\
\hline & & $115(55.28 \%)$ & $176(60.27 \%)$ \\
\hline \multirow{2}{*}{ Hypertension } & & $125(60.09 \%)$ & $137(46.91 \%)$ \\
\hline & & $83(39.9 \%)$ & $155(55.08 \%)$ \\
\hline \multirow{2}{*}{$\begin{array}{l}\text { CAD/ECG } \\
\text { changes }\end{array}$} & & $76(36.5 \%)$ & $16(5.47 \%)$ \\
\hline & & 132( & $\%)$ \\
\hline \multirow{2}{*}{$\begin{array}{l}\text { Recurrent } \\
\text { stroke }\end{array}$} & Present & $99(47.5 \%)$ & $86(29.5 \%)$ \\
\hline & & $109(52.40 \%)$ & $206(70.54 \%)$ \\
\hline \multirow{5}{*}{ HbA1c } & & $4(1.92 \%)$ & $268(92.4 \%)$ \\
\hline & $5.8-6$ & $24(11.5 \%)$ & $22(7.6 \%)$ \\
\hline & $6.6-7.5$ & $62(29.8 \%)$ & $2(0.68 \%)$ \\
\hline & 7.6-8.5 & $60(28.8 \%)$ & 0 \\
\hline & $>8.5$ & $58(27.88 \%)$ & 0 \\
\hline \multicolumn{4}{|c|}{$\begin{array}{l}\text { Table 2. Risk Factors of Diabetic and Non-Diabetic Stroke } \\
\text { Patients }\end{array}$} \\
\hline
\end{tabular}

In our study hypertension was present in $50.6 \%$ of total patients. In diabetic group it was present in $60.09 \%$ and in non-diabetic in $46.91 \%$ and this was significant ( $p$ value0.00046). Majority of the patients in non-diabetic and diabetic had normal ECG. But in diabetics $36.5 .5 \%$ had ECG suggestive of ischemia. p-value 0.0001. Thus, a significant association was there between Ischemic heart disease with DM.

Recurrent stroke is $47.5 \%$ among diabetic patient and $29.5 \%$ among nondiabetic patients. $p$ value is $<0.0001$.

Mean HbA1c \pm SD in the study group was $6.15 \pm 1.51$. in diabetics Mean HbA1c \pm SD was $7.697 \pm 1.095$ and in nondiabetics Mean HbA1c \pm SD was $5.06 \pm 0.439 . \% .86 .5 \% \%$ of the diabetic patients had $\mathrm{HbA1c}>6.5$ reflecting poor glycaemic control. $99.3 \%$ patients in non-DM group had HbA1c $<6.5$.

\begin{tabular}{|c|c|c|c|}
\hline Type of Stroke & HbA1c $\geq \mathbf{6 . 5}$ & HbA1c $<6.5$ & Total \\
\hline Ischemic & 175 & 189 & 364 \\
\hline Haemorrhagic & 09 & 127 & 136 \\
\hline Table 3. Distribution of Patients of Stroke according to \\
HbA1c Levels and Type of Stroke \\
\hline
\end{tabular}

This finding is significant ( $p$-value was<.05). HbA1c is positively associated with ischemic stroke.

\begin{tabular}{|c|c|c|c|}
\hline $\begin{array}{c}\text { Duration of } \\
\text { Diabetes }\end{array}$ & > 5 Year & 1-5 Year & $<$ 1 Year \\
\hline Ischemic & $88(94.7 \%)$ & $62(87.5 \%)$ & $20(92.8 \%)$ \\
\hline Haemorrhagic & $9(5.3 \%)$ & $15(12.5 \%)$ & $14(7.2 \%)$ \\
\hline Total & 97 & 76 & 35 \\
\hline Table 4. Distribution of Diabetic Patients of Stroke \\
according to Duration of Diabetes and Type of Stroke \\
\hline
\end{tabular}

The duration of diabetes increases chances of ischemic stroke ( $p$-value was<.05).

\section{DISCUSSION}

Out of 500 stroke patients 364 (72.8\%) having ischemic stroke and 136 (27.25\%) having haemorrhagic stroke compared to studies like that done by Krishnamurthi RV et al[6]and Aiyar I et al[7] in which infarction was present in $70 \%$.

In our study $81.73 \%$ of diabetic patients had ischemic stroke, these findings are similar to studies like European multicentre study done by Megherbi SE et al[8] where it was concluded that ischemic stroke was more prevalent in diabetics. $18.27 \%$ patients had haemorrhagic stroke all of which were hypertensive suggesting uncontrolled blood pressure could have possibly leads to intracerebral haemorrhage.

In our study 272 (54.45\%) patients were rural and 228 (45.6\%) patients were urban. The prevalence of stroke was slightly higher in rural population which correlates with the study done by Basri Ret al[9]

In our study male to female ratio was 1.52:1. Which correlates with the study of Vaidya $C$ et al[10](1.4:1). So it can be concluded that incidence of stroke is more common in male.

\section{Age Wise Distribution of Stroke Patients}

The mean age \pm SD in present study was $60.86 \pm 12.51$ years compared to study done by Vaidya $\mathrm{C}$ et al[10] and Maskey $\mathrm{A}$ et al[11] where it was 61 and 63 year respectively. The major age group was $>70$ year followed by $61-70$ years compared to study done by Vaidya $\mathrm{C}$ et al ${ }^{[10]}$ and similar study by Ukoha OB et al.[12] Mean age \pm SD in diabetic group was $59.25 \pm$ 11.13 years compared to 55.6 years in study done by Nomani $\mathrm{AZ}$ et al.[13] Mean age \pm SD was $62.03 \pm 13.30$ years in nondiabetic group compared to study done by Nomani AZ et al.[13] The major age group in diabetic group was 51-60 compared to $>70$ years in non-diabetic group. In this study age was found to be an important factor for ischemic stroke similar to what was concluded from Helsinki Young Stroke Registry which finds the frequency of ischemic stroke rises sharply beginning at the age of 40 .

Young stroke (age $\geq 45$ years) comprised $12.8 \%$ of all patients which closely correlates with study done by Sallam AR et al.[14] (13.6\%).

\section{Percentage of Diabetic Stroke Patients in Study Group}

The percentage of diabetic patients in our study was $41.6 \%$ compared to study done in France, based on national database called Hospital Discharge Diagnosis Records where it was $15 \%$. In the study by Vaidya $C$ et al[10], diabetes patients were $9.3 \%$, by Maskey A et al[11] $(9.3 \%)$.

BMI, Waist Circumference and Waist Hip Ratio of Patients The mean BMI was $21.9 \pm 4.4$, among diabetic it was $25.98 \pm$ 4.50 and among Non-diabetic it was $21 \pm 4.2$ correlate with study done by Ali A et al.[15] 43(20.67\%) had BMI of equal to or more than $30 \mathrm{~kg} / \mathrm{m}^{2}$ (Obese). In diabetic group maximum number of patients $(44.7 \%)$ were belong to $25-29.9 \mathrm{~kg} / \mathrm{m}^{2}$. in nondiabetic group maximum number of patients were belongs to $18.5-24.9 \mathrm{~kg} / \mathrm{m}^{2}$. In our study the prevalence of Obesity (BMI $>30 \mathrm{~kg} / \mathrm{m}^{2}$ ) in diabetic stroke patients was $20.67 \%$ as compared to nondiabetic where it was $11.62 \%$ and 
it was significant (p-value 0.0058 ) which correlates with study done by Sweileh WM et al, [16] where it was $20.2 \%$ and $13.75 \%$ respectively.

Mean Waist circumference \pm SD was $93 \pm 5.35$ among diabetic male it was $95 \pm 4.23$ and in nondiabetic it was $92 \pm$ 5.21 which correlate with study done by Sweileh WM et al.[16]

Mean waist hip ratio \pm SD for male was $92 \pm 0.04$ for diabetic male was $0.93 \pm 0.05$ and for nondiabetic male it was $0.90 \pm 0.06$. Mean waist hip ratio \pm SD for diabetic female was $0.90 \pm 0.08$, and for nondiabetic it was $0.82 \pm 0.06$ which correlate with study done by Ali Aet al.[15]and Sweileh WM et al.[16]

\section{Hypertension in Stroke Patients}

Hypertension was the most common risk factor in our study. It was present in $50.6 \%$ of patients. In diabetic group it was present in $60.09 \%$ which was comparable to the study done by Pell $S$ et al ${ }^{[17]}$ where prevalence of hypertension was $54 \%$ higher in the diabetic patients. Moreover, hypertension increased the probability of suffering ischemic stroke in diabetic patients (p-value 0.01). In nondiabetic group hypertension was present in $47.26 \%$ which was comparable to study done by study done by Eapen et al (40\%),[18] Sallam AR et al[14] (67\%) and Vaidya C et al[10] $34.1 \%$.

\section{Lipid Profile and Dyslipidaemia}

Dyslipidaemia was found in $32.6 \%$ of all patients compared to other studies like Eapen et al (17\%) ${ }^{[18]}$ and Sallam AR et al (13.9\%).[14] Presence of diabetes in patient group having HDL $<40 \mathrm{mg} / \mathrm{dl}$, LDL>100 mg/dl, Triglyceride $>150 \mathrm{mg} / \mathrm{dl}$ was associated with increased probability of ischemic stroke (pvalue $0.0001,0.00025,0.0066$ respectively).

\section{Smoking and Tobacco Chewing}

In our study, percentage of addiction specially tobacco chewing was more as compared to other studies. Smoking was present in $25.8 \%$ of patients in diabetic group it was $32.69 \%$ and in nondiabetic group it was $20.89 \%$, as compared to study done by Vaidya $\mathrm{C}$ et al[10] where it was $14.2 \%$.

Tobacco chewing was present in $41.8 \%$ of patients in diabetic stroke it was $44.7 \%$ and in nondiabetic stroke it was $39.7 \%$, were more as compared to study done by Vaidya $\mathrm{C}$ et al.[10]

\section{History of CAD and ECG Changes}

History and ECG suggestive of CAD was present in $10.4 \%$ of total patients. In diabetic group it was $22.6 \%$. This was comparable to Kaur et al[19] al (6\%)and Eapen et al[18] (9\%), Presence of ECG changes suggestive of CAD had increased the likelihood of ischemic stroke.

\section{HbA1c and Duration of Diabetes}

In our study HbA1c was found to be significantly associated with ischemic stroke. Mean HbA1c \pm SD in study group was $6.15 \pm 1.51$ in diabetics it was $7.69 \pm 1.095$ and in nondiabetics it was $5.06 \pm 0.439$. $86.5 \%$ of the diabetic patients had $\mathrm{HbA1c}>6.5$ reflecting the poor glycaemic control. This was similar to earlier studies like Hiyasama study[20] where in ischemic stroke risk was 3.57 (HbA1c-5.56.4) and $9.65 \%$ (HbA1c $>6.5 \%$ ), Norfolk[21] prospective population shown that relative risk for stroke for participants with HbA1c concentrations 5-5.4, 5.5-6.9, >7 were 0.78 (0.50 to 1.22 ), 0.83 (0.54 to 1.27 ), and 2.83 (1.40 to 5.74), respectively, compared with those with HbA1c < $5 \%$ (10489 subjects).

The Atherosclerosis Risk in Communities (ARIC) Study[22] found that in diabetic group patients the adjusted risk of stroke was 2.33 (95\% CI 1.29-4.21) in highest percentile of HbA1c $(>6.8 \%)$ as compared with the lowest one $(<4.7 \%)$, Nomani AZ et al[13] mean HbA1c values were significantly higher in the diabetes group ( $7.6 \pm 2.1$ vs $6.1 \pm 2.3)(\mathrm{p}<0.05)$.

\section{CONCLUSION}

This study shows that diabetes mellitus increases the risk of ischemic stroke. Diabetic stroke patients were younger as compared to non-diabetic stroke patients. Hypertension, poor glycemic control, dyslipidemia, obesity, smoking and tobacco chewing increases the risk of ischemic stroke. Thus, we can use glycemic control, HbA1c and duration of diabetes as a predictor of stroke. Screening of diabetic patients, better glycaemic control are believed to reduce the risk of stroke.

\section{REFERENCES}

[1] Smith WS, Johnson SC, Claude J, et al. Cerebrovascular diseases. In: Kasper DL, Fauci AS, Hauser SL, et al. eds. Harrison's Principle of internal medicine. 19th edn. New York: McGraw-Hill 2015: p. 2559.

[2] Beckman JA, Creager MA, Libby P. Diabetes and atherosclerosis: epidemiology, pathophysiology and management. JAMA 2002;287(19):2570-81.

[3] Lozano R, Naghavi M, Foreman K, et al. Global and regional mortality from 235 causes of death for 20 age groups in 1990 and 2010: a systematic analysis for the Global Burden of Disease Study 2010. Lancet 2012;380(9859):2095-128.

[4] Das SK, Banerjee TK, Biswas A, et al. A prospective community-based study of stroke in Kolkata, India. Stroke 2007;38(3):906-10.

[5] Mozaffarian D, Benjamin EJ, Go AS, et al. Heart Disease and Stroke Statistics 2016 Update: a report from the American Heart Association. Circulation 2016;133(4):e38-e360.

[6] Krishnamurthi RV, Feigin VL, Forouzanfar MH, et al. Global and regional burden of first-ever ischaemic and haemorrhagic stroke during 1990-2010: findings from the Global Burden of Disease Study 2010. Lancet Glob Health 2013;1(5):e259-e81.

[7] Aiyar I. A study of clinic-radiological correlation in cerebrovascular stroke (A study of 50 cases). Guj Med J 1999;52:58-63.

[8] Megherbi SE, Milan C, Minier D, et al. Association between diabetes and stroke subtype on survival and functional outcome 3 months after stroke: data from the European BIOMED Stroke Project. Stroke 2003;34(3):688-94.

[9] Basri R, Shaik MM, Alam MK, et al. Waist to hip ratio, waist to height ratio and body mass index predict stroke risk in a Bangladeshi population. International Medical Journal 2013;20:740-3. 
[10] Vaidya CV, Majmudar DK. A retrospective study of clinical profile of stroke patients from GMERS Medical College and Hospital, Gandhinagar, Gujarat. Int J Clin Trials 2014;1(2):62-6.

[11] Maskey A, Parajuli M, Kohli SC. A study of risk factors of stroke in patients admitted in Manipal Teaching Hospital, Pokhara. Kathmandu Univ Med J (KUMJ) 2011;9(36):244-7.

[12] Ukoha OB, Ajaegbu O, Eke CO. A review of stroke cases in a military hospital in Nigeria. AFRIMEDIC J 2012;3(2):30-3.

[13] Nomani AZ, Nabi S, Ahmed S, et al. High HbA1c is associated with higher risk of ischaemic stroke in Pakistani population without diabetes. Stroke Vasc Neurol 2016;1(3):133-9.

[14] Sallam AR, Al-Aghbari K, Awn H. The clinical profile of stroke: a Yemeni experience. J Med 2009;43(2):11521.

[15] Ali A, Abbasi SA, Mushtaq S, et al. A comparative study of waist circumference, waist hip ratio and BMI in diabetics and non-diabetic. Ann Pak Inst Med Sci 2017;13(1):27-34.

[16] Sweileh WM, Sawalha AF, Al-Aqad SM, et al. The epidemiology of stroke in northern Palestine: a 1-year, hospital-based study. J Stroke Cerebrovasc Dis 2008;17(6):406-11.
[17] Pell S, D'Alonzo CA. Some aspects of hypertension in diabetes mellitus. JAMA 1967;202(1):104-10.

[18] Eapen RP, Parikh JH, Patel TN. A study of clinical profile and risk factors of cerebrovascular stroke. Guj Med J 2009;64(2):47-54.

[19] Kaur IR, Agarwal MP, Singh NR. Study of clinical profile \& CT correlation in CV stroke. J Assoc Physician India 2001;51:112-7.

[20] Ikeda F, Doi Y, Ninomiya T, et al. Haemoglobin A1c even within non-diabetic level is a predictor of cardiovascular disease in a general Japanese population: the Hisayama Study. Cardiovasc Diabetol 2013;12:164.

[21] Myint PK, Sinha S, Wareham NJ, et al. Glycated hemoglobin and risk of stroke in people without known diabetes in the European Prospective Investigation into Cancer (EPIC)-Norfolk prospective population study: a threshold relationship? Stroke 2007;38(2):271-5.

[22] Selvin E, Coresh J, Shahar E, et al. Glycaemia (haemoglobin A1c) and incident ischaemic stroke: the Atherosclerosis Risk in Communities (ARIC) Study. Lancet Neurol 2005;4(12):821-6. 